\title{
Psychopathic personality and utilitarian moral judgment in college students
}

ARTICLE in JOURNAL OF CRIMINAL JUSTICE · SEPTEMBER 2013

Impact Factor: 1.24 · DOI: 10.1016/j.jcrimjus.2013.06.012

2 AUTHORS, INCLUDING:

\section{Yu Gao}

City University of New York - Brooklyn College

29 PUBLICATIONS 469 CITATIONS

SEE PROFILE 


\title{
Psychopathic personality and utilitarian moral judgment in college students
}

\author{
Yu Gao ${ }^{\mathrm{a}, *}$, Simone Tang ${ }^{\mathrm{b}}$ \\ a Department of Psychology, Brooklyn College and the Graduate Center of the City University of New York, Brooklyn, NY, USA \\ ${ }^{\mathrm{b}}$ Fuqua School of Business, Duke University, Durham, NC, USA
}

\section{A R T I C L E I N F O}

Available online 19 July 2013

\begin{abstract}
A B S T R A C T
Purpose: Although psychopathy is characterized by amoral behavior, literature on the association between psychopathy and moral judgment pattern is mixed. Recent evidence suggests that this may be due to the moderation effect of anxiety (Koenigs, Kruepke, Zeier, \& Newman, 2011). The current study aims to examine the psychopathy-utilitarian judgment association in college students.

Method: In this study, a group of 302 college students completed a moral judgment test involving hypothetical dilemmas. Their psychopathic traits were assessed by the Psychopathic Personality Inventory - Short Form (PPI-SF) (Lilienfeld \& Andrews, 1996).

Results: Individuals with higher psychopathic traits were more likely to make utilitarian responses to moral dilemmas. Furthermore, the association between utilitarian responses and psychopathy was more salient for the behavioral factor of psychopathy (PPI-II), and this association was mediated by self-reported aggression. However, the moderating effect of anxiety was not found.

Conclusions: These results build upon work on utilitarian moral judgment in psychopathic individuals in a non-incarcerated, non-institutionalized sample, and have important implications for the behavioral correction system.
\end{abstract}

(c) 2013 Elsevier Ltd. All rights reserved.

\section{Introduction}

Psychopathy is a constellation of personality traits characterized by callous and impulsive antisocial behavior. Emotional deficits, in particular low fear reactivity, and behavioral dysregulation have been argued to be the core processes in the development of psychopathy (Fowles \& Dindo, 2009; Hare, 2003; Patrick, Bradley, \& Lang, 1993). Unsurprisingly, their emotional and behavioral traits have devastating effects on society. According to Kiehl and Buckholtz (2010), psychopaths cost the nation roughly $\$ 250$ to $\$ 400$ billion a year due to trials, prison stays and inflicted damage. Bernard Madoff, the psychopathic operator of one of the largest financial frauds in the U.S., stole about $\$ 65$ billion from his clients. And psychopaths are not just isolated to the few "bad, corrupt apples" at the top. Psychopaths exploit the trust of coworkers and their managers, and manipulate friends and strangers (Babiak \& Hare, 2007; Coid, Yang, Ullrich, Roberts, \& Hare, 2009). Yet although psychopaths have such a devastating effect on society, there is only limited experimental data on how they form moral judgments.

One moral decision-making task that has been used to explore the psychological and neurobiological processes underlying moral judgment in psychopathy is the scenario task. In its general form,

\footnotetext{
* Corresponding author at: Department of Psychology, Brooklyn College, 2900 Bedford Avenue, 5401 James Hall, Brooklyn, NY 11210. Tel.: + 1718951 5000x6033; fax: + 1718 9514814.

E-mail address: yugao@brooklyn.cuny.edu (Y. Gao).
}

participants read a hypothetical scenario, and are asked to decide whether they would commit some harm in order to achieve a certain goal. Based on Greene's dual process theory, there are two competing processes, supported by neurological systems, which are part of making moral judgments. On one hand, we may strongly feel that an action is inherently wrong. On the other hand, we may engage in cost-benefit analysis and decide that the action can serve the greater good. Greene uses this theory to explain why people report being unwilling to push a man down a footbridge to stop a trolley from running over five people, and yet are willing to flip a switch so that the trolley changes course to hit one man rather than five. In the first, "personal" moral scenario, a dominant, negative emotional response is associated with the action, which elicits moral disapproval. In contrast, the latter, "impersonal" moral scenario does not have any associated dominant response, and thus produces a rational utilitarian decision (Greene, 2007; Greene, Nystrom, Engell, Darley, \& Cohen, 2004; Greene, Sommerville, Nystrom, Darley, \& Cohen, 2001).

This theory has been supported by brain imaging data which have identified that during moral decision-making tasks the "executive brain center" - prefrontal cortex - is associated with rational processing (Forbes \& Grafman, 2010; Young \& Koenigs, 2007) whereas emotional regions including anterior temporal lobes and anterior cingulate gyrus are involved in emotional processing (Robertson et al., 2007). In addition, patients with fronto-temporal lobe dementia or ventromedial prefrontal cortex damage who have noted emotional deficits, have also shown more utilitarian responses (Ciaramelli, Muccioli, Ladavas, \& di 
Pellegrino, 2007; Koenigs et al., 2007; Moretto, Ladavas, Mattioli, \& di Pellegrino, 2010). Taken together, these findings suggest that brain regions including the anterior cingulate cortex, the ventromedial prefrontal cortex, the amygdala, and hippocampus are critically involved in moral reasoning.

Given the critical role of emotion in moral judgment and striking social/emotional deficits observed in psychopaths, one might expect to find more utilitarian judgment in individuals with high psychopathic traits. However, the evidence has been mixed. Using Greene's moral task, some empirical studies have supported this hypothesis (Bartels \& Pizarro, 2011; Landon \& Delmas, 2012), whereas others have failed to find the association between psychopathy and utilitarian preferences (Cima, Tonnaer, \& Houser, 2010; Glenn, Raine, \& Schug, 2009; Pujol et al., 2011). Despite the mixed findings at the behavioral level, fMRI data have indicated that reduced activity in regions including ventromedial prefrontal cortex and amygdala during the evaluation of moral dilemmas is associated with psychopathy scores (Glenn et al., 2009). In addition, a baseline network alteration that leads to a functional disconnection between emotional and cognitive elements in moral judgment has also been found in criminal psychopaths (Pujol et al., 2011).

Koenigs and colleagues (2011) have hypothesized that failure to find the association between psychopathy and utilitarian moral judgment may be due to the heterogeneity of the group. In a group of incarcerated males, they found that although compared to non-psychopathic controls, both low- and high-anxious psychopaths are more likely to endorse the impersonal moral actions, only the low-anxious psychopath exhibit abnormally utilitarian personal moral judgment (Koenigs et al., 2011), suggesting that anxiety may moderate the relationship between psychopathy and moral judgment. However, it is unknown if these associations between psychopathy, anxiety, and utilitarian responses can be generalized in non-institutionalized populations. In the current study, the State and Trait Anxiety Inventory (STAI) - Trait scale (Spielberger, Gorsuch, Lushene, Vagg, \& Jacobs, 1983) was used to assess anxiety level in college students. This 20 -item scale has been used in several studies to examine the associations between anxiety and psychopathic traits (Uzieblo, Verschuere, \& Crombez, 2007) in college samples.

The goal of the current study was to examine the association between psychopathic personality traits and moral judgment in a non-clinical, non-forensic sample. Although Bartels and Pizarro (2011) found that psychopathic personality traits, as measured by the Self-Report Psychopathy form (Paulhus, Hemphill, \& Hare, 2012), were positively associated with utilitarian responses to moral dilemmas, it was unclear which of the factor(s) of psychopathy would be associated with utilitarian moral responses. This issue is important as this has implications for gaining a more comprehensive picture of the processes behind psychopathy and moral decision-making. Thus, one of the goals of this study was to explore the factor(s) associated with utilitarian moral judgments.

In the current study, we assessed psychopathic traits using the Psychopathic Personality Inventory - Short Form (PPI-SF; Lilienfeld \& Andrews, 1996). The Psychopathic Personality Inventory (PPI; Lilienfeld \& Andrews, 1996) is one of the most widely used instruments to assess psychopathic characteristics in undergraduate samples, and the PPI-short form (PPI-SF) was developed from the original PPI and includes 56 items. In a sample of 758 college students a three-factor model (PPI-I, PPI-II, and Coldheartedness) has been derived with the PPI-SF (Smith, Edens, \& Vaughn, 2011). Studies have suggested that PPI-I is strongly positively associated with interpersonal dominance, and negatively related to internalizing psychopathology, including anxiety and depression (Benning, Patrick, \& Iacono, 2005; Edens \& McDermott, 2010; Lilienfeld \& Widows, 2005). In contrast, PPI-II tends to be positively correlated with internalizing measures and is positively correlated with externalizing measures including impulsivity, hostility, and aggression (Edens \& McDermott, 2010; Lilienfeld \& Widows, 2005). Behavioral genetic studies have indicated that PPI-I was associated with a reduced genetic risk for internalizing disorders, and PPI-II was associated with an increased genetic risk for externalizing disorders (Blonigen, Hicks, Krueger, Patrick, \& Iacono, 2005). More interestingly, Smith and colleagues (2011) have found that PPI-II is positively associated with Machiavellianism and deception and negatively correlated with extraversion. Since greater endorsement of utilitarian solutions have been found to be positively related to Machiavellianism (Bartels \& Pizarro, 2011), we hypothesize that utilitarian judgment will be more closely related to PPI-II than PPI-I.

Another issue concerns the possible mediating effect of aggression on the relationship between psychopathy and moral judgment. A mediation relationship is said to occur when the predictor variable influences the outcome indirectly through its relationship with a mediating variable (Baron \& Kenny, 1986). Significant associations have been found between psychopathy and aggression (Porter \& Woodworth, 2006), but no study has yet examined the link between aggression and moral judgment. It is possible that people high in psychopathic personality are simply more aggressive and thus willing to endorse killing actions. It is therefore also important to investigate if high aggression could partly account for the association between psychopathy and utilitarian judgment. Given that PPI-II but not PPI-I is associated with aggressive behavior, we hypothesize that aggression may mediate the association between PPI-II and utilitarian judgments.

\section{The present study}

We examine the associations between utilitarian judgment, psychopathic personality traits, anxiety, and aggression in a group of male and female college students. Based on Koenigs et al. (2011)'s finding, we hypothesize that:

1) Individuals with high psychopathic personality traits would be more likely to make utilitarian judgments for impersonal and personal moral dilemmas.

2) The association between psychopathy and utilitarian response to personal moral dilemmas would be moderated by anxiety: only individuals with high psychopathy AND low anxiety would show significantly more utilitarian responses to personal moral dilemmas.

3) Utilitarian moral judgment would be more closely related to PPI-II but not PPI-I, and this association would be mediated by self-report aggression.

\section{Method}

\section{Participants}

Three hundred and two undergraduate students (73\% females, mean age $=21.97, \mathrm{SD}=6.19$ ) from an urban college participated for course credit. They were from diverse racial and ethnic backgrounds: 39.6\% Caucasian, 25.2\% Asian, 14.4\% African American, 11.7\% Hispanic, and $9.1 \%$ from other racial backgrounds. They were tested in a small group setting (typically one to five participants per session). Participants responded to 15 dilemmas and a series of self-report questionnaires measuring their psychopathic personality traits, trait anxiety, aggression, and demographic information. All procedures were approved by the university IRB, and informed consent was obtained from all participants.

\section{Measures}

\section{Moral dilemmas}

A total of 15 dilemmas (4 non-moral, 4 impersonal moral, and 7 personal moral scenarios, see Appendix A) selected from a previously published set (Greene et al., 2001; Koenigs et al., 2007) were presented in random order. To be consistent with the question format used in previous studies (Cima et al., 2010; Koenigs et al., 2011), 
participants were asked to answer "Yes" or "No" to the hypothetical questions relating to the dilemmas, in the form of, "Would you ... in order to ...?" In non-moral dilemmas, participants were asked to make decisions that involved no harm. For example, they had to decide whether to substitute preferred macadamia nuts for walnuts in a batch of brownies, even though the recipe called for walnuts. Non-moral dilemmas served as a control and baseline condition. In impersonal moral dilemmas, participants were asked to make decisions that involved harm, but did not require them to directly commit harm to another person. For example, they were asked to decide whether they would flip a switch so that noxious fumes from a room with three people would flow into a room with one person. In personal moral dilemmas, participants were asked to make decisions that involved harm, but this time required them to directly commit harm to another person. For example, they had to decide whether to transplant the organs of a relatively healthy patient to five dying patients. "Yes" responses corresponded to "utilitarian" decisions that maximized utility or the greater good (Greene, 2003). There was no time limit for reading the scenario description or responding to the question. Following the method of Koenigs et al. (2011), the proportion of "yes" responses for each type of scenario was calculated for each individual.

Psychopathic personality inventory - short form (PPI-SF Lilienfeld E Andrews, 1996)

Psychopathic personality was assessed using the PPI-SF and participants answered on a 4-point Likert scale $(1=$ false, $2=$ mostly false, $3=$ mostly true, $4=$ true). The PPI-SF consists of eight subscales with internal consistencies, as measured by Cronbach's alpha for the undergraduate sample, ranging from .63 to .80 (Smith et al., 2011), and has good test - retest reliability (Lilienfeld \& Andrews, 1996; Poythress, Edens, \& Lilienfeld, 1998). More recent factor analysis by Benning et al. (2003) and Smith et al. (2011) on these eight subscales revealed evidence for two largely orthogonal factors. Factor 1(PPI-I) is the sum of the standardized scores on Stress Immunity, Social Potency, and Fearless subscales, while Factor 2 (PPI-II) is the sum of the standardized scores on Blame Externalization, Machiavellian Egocentricity, Carefree Nonplanfulness, and Impulsive Nonconformity. The eighth subscale, Coldheartedness, failed to load substantially onto either factor (Benning, Patrick, Hicks, Blonigen, \& Krueger, 2003; Smith et al., 2011). Internal consistency in the current sample for the subscales ranged from .50 (Coldheartedness) to .81 (Blame Externalization). In the following analyses, PPI-I, PPI-II, Coldheartedness, and PPI total score (sum of the eight subscales) were used.

Reactive-Proactive Aggression Questionnaire (RPQ Raine et al., 2006)

$\mathrm{RPQ}$ was used to indicate predatory (proactive) and impulsive (reactive) dimensions. The RPQ consists of 23 items of which 12 items make up the proactive subscale (e.g. "How often have you got others to gang up on someone else?") and 11 make up the reactive subscale (for example "How often have you gotten angry or mad or hit others when teased?"). Earlier studies have shown good internal reliabilities for total RPQ with reactive and proactive subscale scores all above .81 (Raine et al., 2006).The RPQ has demonstrated good validity and the two factors of reactive and proactive aggression have been substantiated with confirmatory factor analysis (Raine et al., 2006). Internal consistency in the current sample was .82 for the total RPQ. For the reactive subscale internal consistency was .76, for the proactive subscale it was .69 .

The State-Trait Anxiety Inventory -Trait version (STAI-T, Spielberger, Gorsuch, Lushene, Vagg, EJ Jacobs, 1983)

The STAI-T is a questionnaire comprising of 20 items designed to measure trait anxiety (e.g. "I worry too much over something that really doesn't matter"). Participants answer according to how they generally feel on a 4 -point Likert scale $(1=$ almost never,
$2=$ somewhat, $3=$ moderately, and $4=$ very much). It assesses trait anxiety, but also relates to measures of depression and negative affect (Bados, Gomez-Benito, \& Balaguer, 2010). We used the STAI-T because of its wide usage, history of good internal reliability, good test-retest reliability, and good convergent validity (Antony, Orsillo, \& Roemer, 2001; Spielberger, 1989; Spielberger et al., 1983). In addition, we used the trait version rather than the state version because it is more theoretically consistent with our hypotheses - we are interested not in how anxiety at a particular moment would affect the relationship between psychopathy and moral judgments. Rather, we are interested in how a general feeling of anxiety is likely to moderate the relationship. Internal consistency in the current sample was .90.

\section{Statistical analyses}

Paired sample t-tests were conducted to compare participants' responses to different types of dilemmas. Effect sizes were reported using Cohen's $d$ (Cohen, 1988). Multiple regressions were used to examine the relationships between psychopathic traits and utilitarian responses. To test for potential moderating effects of anxiety, hierarchical multiple regression analyses were conducted for the proportion of "yes" responses to overall moral dilemmas, personal moral dilemmas, and impersonal moral dilemmas separately. For these analyses, anxiety and PPI-total score were entered by subtracting the sample mean from each participant's score. In step 1, the proportion of "yes" responses was regressed onto gender and PPI-total score. In step 2, the main effect of anxiety and a multiplicative interaction term was entered into the equation to test for the interaction between anxiety and psychopathy.

To examine the potential mediating effect of aggression, we first followed Baron and Kenny (Baron \& Kenny, 1986)'s criteria to assess if true mediation was present. The paths between independent, dependent and mediator variables were assessed by ordinary least squares (regression). The Sobel test (Sobel, 1982) was used to test whether the mediator significantly attenuated the influence of the independent variable on the dependent variable. Finally, a 2-step regression analysis was conducted to examine if any remaining relationship between psychopathy and utilitarian responses was still significant after controlling for the aggression mediator.

\section{Results}

\section{Moral (impersonal vs. personal) vs. non-moral dilemmas}

We first compared participants' responses between moral and non-moral scenarios. The proportion of "yes" responses to moral dilemmas was significantly lower than that to non-moral dilemmas $(t(301)=29.16, p<.001$; for moral dilemmas, $M=.40, S D=.19$; for non-moral dilemmas, $M=.85, S D=.19, d=2.37$ ). Participants also gave fewer utilitarian responses (i.e. smaller proportion of "yes" responses) to personal compared to impersonal moral dilemmas $(t(301)=4.15, p<.001$; personal moral dilemmas, $M=.38$, $S D=.25$; impersonal moral dilemmas, $M=.44, S D=.22, d=0.24$ ) (Fig. 1).

\section{Psychopathic personality and utilitarian responses}

Table 1 shows inter-correlations among main study variables. Participants who had higher PPI total scores (overall psychopathy) indicated a greater preference for "yes" responses to the moral dilemmas. This was true for the overall analysis, when responses across all 11 moral dilemmas were collapsed $(r=.16, p<.01)$, as well as for the personal moral dilemmas in particular $(r=.14, p=.02)$. The relationship between PPI total scores and utilitarian responses to impersonal moral dilemmas approached significance $(r=.11, p=.05)$. Consistent with our third hypothesis, these significant relations with 


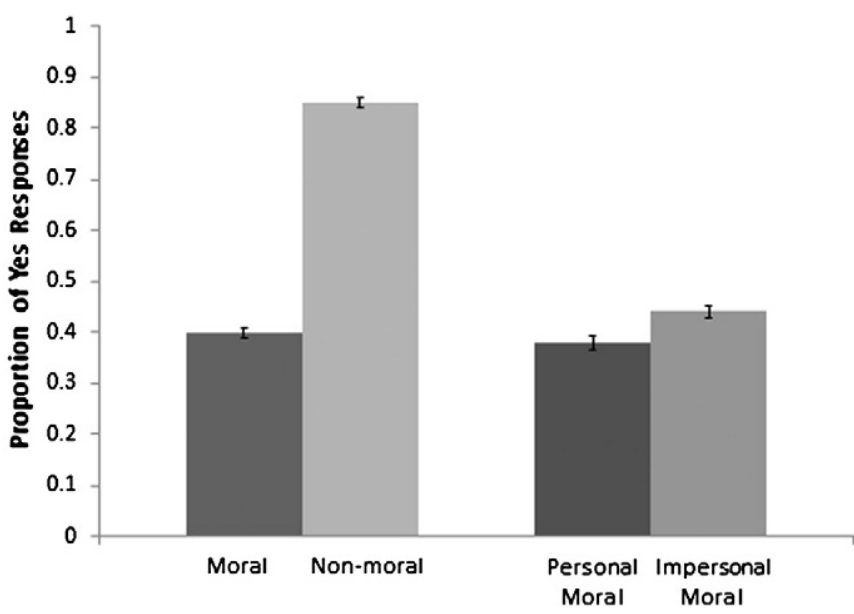

Fig. 1. Proportion of "yes" responses to overall moral, non-moral, personal, and impersonal dilemmas in college students. Bars refer to 1 standard error of the mean.

utilitarian responses were mainly driven by PPI-II ( $r \mathrm{~s}=.18$ to .24 , $p<.05$ ). PPI-I was not correlated with any of the decision variables.

Compared to females, males scored significantly higher on PPI total (male $M=129.39, S D=13.99$, female $M=119.49, S D=13.72$, $d=0.71$ ) and factor scores (PPI-I, male $M=0.28, S D=.77$, female $M=-.10, S D=0.66, d=0.53$; PPI-II, male $M=0.20, S D=0.61$, female $M=-0.07, S D=0.62, d=0.44$; and Coldheartedness, male $M=0.21, S D=1.06$, female $M=-0.08, S D=0.97, d=0.29$ ). Males also scored lower on anxiety (male $M=40.88, S D=9.85$, female $M=45.22, S D=10.61, d=-0.42$ ) and were more likely to make utilitarian responses to personal moral dilemmas (male $M=0.47$, $S D=0.26$, female $M=0.34, S D=0.23, d=0.53$ ). However, males did not differ from females in their responses to impersonal moral, non-moral dilemmas or reported aggression.

To control for the observed effects of gender on the responses to moral dilemmas, we conducted multiple regressions for the utilitarian responses using PPI-II as a predictor while controlling for gender. As Table 2 shows, the relationship between utilitarian preferences and PPI-II was robust even when gender was taken into account. ${ }^{1}$

\section{Moderating effect of anxiety}

Anxiety was not correlated with any of the decision measures. Hierarchical multiple regression analyses were conducted to test for
Table 2

Relationships between PPI-II and utilitarian responses, controlling for gender standardized betas

\begin{tabular}{lll}
\hline & PPI-II & Gender $(1=$ Male, $2=$ Female $)$ \\
\hline Moral & $.21^{* * *}$ & $-.12^{*}$ \\
Personal Moral & $.17^{* *}$ & $-.19^{* *}$ \\
Impersonal Moral & $.19^{* *}$ & .06 \\
\hline
\end{tabular}

potential moderating effects of anxiety. As shown in Table 3, there was no significant interaction between anxiety and psychopathy for the utilitarian responses to overall moral dilemmas or personal moral dilemmas. For impersonal moral dilemmas, the addition of an interaction term and anxiety added 3\% of the variance to the prediction of the utilitarian responses, and the interaction between total psychopathy and anxiety approached significance $(p=.06)$. Similar analyses were conducted with PPI-II replacing PPI-total in the equations. There was no significant interaction between anxiety and PPI-II in predicting for utilitarian responses to any type of the moral dilemmas. Thus, our second hypothesis was not supported.

\section{Mediating effect of aggression}

As can be seen in Table 1, participants who scored higher on aggression measures were more likely to make utilitarian responses for overall moral dilemmas, in particular the impersonal moral dilemmas $(r=.14$ to $.33, p<.05$ ). None of the aggression variables were significantly correlated to responses to personal moral or non-moral dilemmas. Since proactive and reactive aggression showed similar relationship to all other variables (see Table 1), the following analyses were conducted using total aggression score.

After controlling for total aggression, the amount of variance in utilitarian responses to overall moral dilemmas explained by PPI-II was reduced from $5.6 \%(F=17.88, p<.001)$ to $1.7 \%(F=3.77$, $p=.05)$. The Sobel test showed that this reduction was statistically significant $(z=3.36, p<.001)$. Similarly, the amount of variance in utilitarian responses to impersonal moral dilemmas explained by PPI-II was reduced from $3 \%(F=6.75, p=.01)$ to $0.1 \%$ after controlling for aggression. The Sobel test showed that this was a statistically significant reduction $(z=4.90, p<.01)$. Regression analyses indicated that the residual variance in utilitarian responses explained by PPI-II after controlling for aggression was no longer significant $(F=0.04, p=.84)$, suggesting that aggression completely mediated the psychopathy-

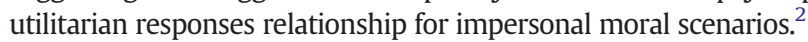

Table 1

Intercorrelations between main study variables, together with means and SDs

\begin{tabular}{|c|c|c|c|c|c|c|c|c|c|c|c|c|c|}
\hline & PPI-total & PPI-I & PPI-II & Coldheartedness & Anxiety & Aggression & $\begin{array}{l}\text { Proactive } \\
\text { aggression }\end{array}$ & $\begin{array}{l}\text { Reactive } \\
\text { aggression }\end{array}$ & Moral & $\begin{array}{l}\text { Personal } \\
\text { moral }\end{array}$ & $\begin{array}{l}\text { Impersonal } \\
\text { moral }\end{array}$ & Non-moral & $\begin{array}{l}\text { Gender } \\
(1=\mathrm{M} \text {, } \\
2=\mathrm{F})\end{array}$ \\
\hline PPI-total & 1 & $.73^{* * *}$ & $.69^{* * *}$ & $.32^{* * *}$ & -.09 & $.33^{* * *}$ & $.39^{* * *}$ & $.21^{* *}$ & $.16^{* *}$ & $.14^{*}$ & $.11^{\mathrm{a}}$ & -.03 & $-.30^{* * *}$ \\
\hline PPI-I & & 1 & .06 & $.19^{* *}$ & $-.41^{* * *}$ & .05 & $.13^{\mathrm{a}}$ & -.02 & -.01 & -.01 & -.01 & .09 & $-.24^{* * *}$ \\
\hline PPI-II & & & 1 & -.02 & $.39 * * *$ & $.50^{* * *}$ & $.50^{* * *}$ & $.41^{* * *}$ & $.24^{* * *}$ & $.21^{* * *}$ & $.18^{* *}$ & -.09 & $-.19^{* *}$ \\
\hline Coldheartedness & & & & 1 & $-.31^{* * *}$ & $-.18^{* *}$ & -.09 & $-.22^{* *}$ & .03 & .04 & -.01 & $-.14^{*}$ & $-.13^{*}$ \\
\hline Anxiety & & & & & 1 & $.21^{* *}$ & .12 & $.24^{* *}$ & .11 & .08 & .09 & -.06 & $.18^{*}$ \\
\hline Aggression & & & & & & 1 & $.86^{* * *}$ & $.91^{* * *}$ & $.21^{* *}$ & .09 & $.33^{* * *}$ & -.08 & -.07 \\
\hline Proactive Aggression & & & & & & & 1 & $.58^{* * * *}$ & $.14^{*}$ & .03 & $.29^{* * * *}$ & -.06 & -.11 \\
\hline Reactive Aggression & & & & & & & & 1 & $.23^{* *}$ & $.12^{\mathrm{a}}$ & $.30^{* * *}$ & -.09 & -.03 \\
\hline Moral & & & & & & & & & 1 & $.92^{* * *}$ & $.63^{* * *}$ & .03 & $-.16^{* *}$ \\
\hline Personal Moral & & & & & & & & & & 1 & $.27^{* * *}$ & .02 & $-.22^{* * *}$ \\
\hline Impersonal Moral & & & & & & & & & & & 1 & .04 & .03 \\
\hline Non-moral & & & & & & & & & & & & 1 & -.02 \\
\hline Gender & & & & & & & & & & & & & 1 \\
\hline Mean & 122.13 & 0.00 & 0.00 & 0.00 & 44.16 & 12.51 & 2.97 & 9.25 & .40 & .38 & .44 & .85 & - \\
\hline SD & 14.47 & .71 & .63 & 1.00 & 10.60 & 5.92 & 3.02 & 3.79 & .19 & .25 & .22 & .19 & - \\
\hline
\end{tabular}

Note.

${ }^{*} p<.05,{ }^{* *} p<.01,{ }^{* * *} p<.001,{ }^{\mathrm{a}} p<.10$. 
Table 3

Hierarchical regression analyses testing for the potential moderating role of anxiety

\begin{tabular}{|c|c|c|c|c|c|c|c|c|c|}
\hline & \multicolumn{3}{|l|}{ Moral } & \multicolumn{3}{|c|}{ Personal Moral } & \multicolumn{3}{|c|}{ Impersonal Moral } \\
\hline & $\bar{\beta}$ & $\mathrm{R}^{2}$ & $\mathrm{R}^{2}$ change & $\bar{\beta}$ & $\mathrm{R}^{2}$ & $\overline{\mathrm{R}^{2} \text { change }}$ & $\bar{\beta}$ & $\mathrm{R}^{2}$ & $\mathrm{R}^{2}$ change \\
\hline \multicolumn{10}{|l|}{ PPI-total } \\
\hline Gender & $-.20^{* *}$ & & & $-.27^{* * *}$ & & & .04 & & \\
\hline PPI-T & .06 & & & .03 & & & .07 & & \\
\hline & & 0.05 & & & .08 & & & .01 & \\
\hline Gender & $-.24^{* *}$ & & & $-.30^{* * *}$ & & & -.01 & & \\
\hline PPI-T & .06 & & & .04 & & & .08 & & \\
\hline Anxiety & $.15^{*}$ & & & $.13^{\mathrm{a}}$ & & & .10 & & \\
\hline \multirow[t]{2}{*}{ Anxiety $\times$ PPI-T } & .07 & & & .01 & & & $.14^{\mathrm{a}}$ & & \\
\hline & & 0.08 & $0.03^{\mathrm{a}}$ & & .10 & .02 & & .03 & $.03^{\mathrm{a}}$ \\
\hline \multicolumn{10}{|l|}{ PPI-II } \\
\hline Gender & $-.19 *$ & & & $-.26^{* *}$ & & & .04 & & \\
\hline \multirow[t]{2}{*}{ PPI-II } & $.19 *$ & & & $.17^{*}$ & & & .11 & & \\
\hline & & .08 & & & .11 & & & .01 & \\
\hline Gender & $-.21^{* *}$ & & & $-.27^{* * *}$ & & & .02 & & \\
\hline PPI-II & $.16^{\mathrm{a}}$ & & & $.14^{\mathrm{a}}$ & & & .10 & & \\
\hline Anxiety & .07 & & & .07 & & & .03 & & \\
\hline \multirow[t]{2}{*}{ Anxiety $\times$ PPI-II } & .04 & & & -.01 & & & .10 & & \\
\hline & & .09 & .01 & & .11 & .01 & & .02 & .01 \\
\hline
\end{tabular}

\section{Discussion}

In this study, we investigated the association between psychopathic traits and moral judgments. Results supported our first and third hypotheses. As expected, individuals with high psychopathic traits were generally more willing than those with low traits to endorse impersonal or personal harms or rule violations in order to achieve certain beneficial outcomes. More interestingly, utilitarian responses to personal and impersonal moral dilemmas were positively correlated with the second factor of PPI (PPI-II, including Blame Externalization, Machiavellian Egocentricity, Carefree Nonplanfulness, and Impulsive Nonconformity) but not the first factor (PPI-I, including Stress Immunity, Social Potency, and Fearlessness) or Coldheartedness, and the association between psychopathy and utilitarian moral judgments was mediated by aggressive behavior. Our second hypothesis, however, was not supported: anxiety did not moderate the association between psychopathy and utilitarian response to personal moral dilemmas.

Our finding suggests that the association between utilitarian judgment and psychopathic traits is mainly driven by these externalizing characteristics rather than the affective/interpersonal factor of psychopathy. As mentioned in the introduction, PPI-I and PPI-II largely represent a global indicator of (reduced) internalizing and (increased) externalizing psychopathology, respectively. These differential relationships further demonstrate that it is critical to disaggregate potentially heterogeneous psychopathological and personality constructs into narrower, homogeneous components (Fowles \& Dindo, 2009; Lynam \& Widiger, 2007; Smith et al., 2011) to fully understand the mechanism and processes underlying moral judgments in psychopathic individuals.

In contrast to our prediction, we failed to find moderating effect of anxiety, suggesting that the behavioral/emotional deficit that gives rise to utilitarian judgments characterizes all those who score high on psychopathic traits, regardless of anxiety level. One possible reason for the discrepant finding from Koenigs et al. (2011) is that Koenigs et al. examined the association in an incarcerated sample whereas we focused on non-institutionalized college sample. Different findings seem to suggest that differences between criminal and noncriminal psychopathy are both quantitative and qualitative in nature.

We also found that males gave significantly more utilitarian answers to personal moral dilemmas when compared to females, although there were no gender differences in utilitarian responses to non-moral dilemmas or impersonal moral dilemmas. This was consistent with prior literature (Fumagalli et al., 2010; Youssef et al., 2012), suggesting that the cognitive-emotional processes and the underlying neurobiological mechanisms involved in evaluating personal moral dilemmas differ in males and in females (Fumagalli et al., 2010). Although Coldheartedness was negatively correlated with the proportion of "yes" responses to non-moral dilemmas, it was not significantly correlated with the utilitarian responses to personal or impersonal moral dilemmas in our study. This may be due to the relatively low internal reliability of the subscale (alpha $=.50$ ), and a Type II error is possible. Nevertheless, we found Coldheartedness to be significantly correlated with PPI-I but not PPI-II, which are consistent with prior literature (Smith et al., 2011).

One of the limitations of the study is that self-report scales were used throughout this research. Despite its practical and effective quality of assessing traits of interests, this method may be prone to response bias. Although psychopathic traits, aggression, and moral judgment have been found to be significantly related to socially desirable responding (Warren, 2009), the same study has found that socially desirable responding did not have a significant impact on the associations between psychopathy, aggression, and empathy. Nonetheless, future studies could use other measures, such as utilizing role-play in the laboratory or other behavioral paradigms to replicate and build upon this research. The second issue is representativeness. There were significantly more females than males in our sample, although in the general population psychopaths are predominantly males. This was mainly due to the gender imbalance inherent within the psychology course make-up at the college, with approximately $70-80 \%$ of psychology students being female. Although we controlled for the effect of gender in the analyses, future studies with a large sample or an equal number of males and females are required to investigate the effect of gender imbalance on the associations of interest. Additionally, despite our participants being ethnically and socioeconomically diverse, we used a convenience sample of college students. They may differ qualitatively from those who have been convicted or incarcerated, and hence the relationship between the dimensions of psychopathic traits may relate differently to moral judgments. This, in turn, would imply different antisocial behavior prevention strategies for the two sets of populations.

\section{Conclusions}

In addition to building upon prior research on moral decisionmaking of psychopaths, our research has contributed to the understanding of the specific factors of psychopathy that are associated with utilitarian decision-making. Our results suggest that externalizing traits contribute more strongly to utilitarian responses, and 
this externalizing - utilitarianism association becomes more salient in the impersonal dilemmas when the prepotent negative emotional responses that oppose acts of harm are weaker or nonexistent. Psychopathy incurs an enormous toll on society, and understanding how psychopathic individuals make moral decisions is important. If their tendency to maximize outcome is largely associated with certain characteristics such as blame externalization rather than fearlessness, then correction programs should focus on exercising responsibility rather than trying to intimidate psychopathic offenders with the negative consequences of offending. Thus, for example, the California Department of Corrections and Rehabilitation Honor Program, which emphasizes personal responsibility and commitment to personal growth (Hartman, 2007), may be more successful than a program in which senior inmates recount stories of how their crimes destroyed their futures.

\section{Appendix A}

\section{Non-Moral Scenarios:}

1. You are bringing home a number of plants from a store that is about two miles from your home. The trunk of your car, which you've lined with plastic to catch the mud from the plants, will hold most of the plants you've bought. You could bring all the plants home in one trip, but this would require putting some of the plants in the back seat as well as in the trunk. By putting some of the plants in the back seat you will ruin your fine leather upholstery which would cost thousands of dollars to replace.

Would you make two trips home in order to avoid ruining the upholstery of your car?

2. You have decided to make a batch of brownies for yourself. You open your recipe book and find a recipe for brownies. The recipe calls for a cup of chopped walnuts. You don't like walnuts, but you do like macadamia nuts. As it happens you have both kinds of nuts available to you.

Would you substitute macadamia nuts for walnuts in order to avoid eating walnuts?

3. You need to travel from New York to Boston in order to attend a meeting that starts at 2PM. You can take either the train or the bus. The train will get you there just in time for your meeting no matter what. The bus is scheduled to arrive an hour before your meeting, but the bus is occasionally several hours late because of traffic. It would be nice to have an extra hour before the meeting, but you cannot afford to be late.

Do you take the train or the bus?

4. An old friend has invited you to spend the weekend with him at his summer home some ways up the coast from where you are. You intend to travel there by car, and there are two routes that you can take: the highway and the coastal road. The highway will get you to your friend's house in about three hours, but the scenery along the highway is very boring. The coastal route will get you to your friend's house in about three hours and fifteen minutes, and the scenery along the coastal road is breathtakingly beautiful. Would you take the coastal route (scenic but slower) or the highway (boring but faster)?

Impersonal Moral Scenarios:

5. You are the late-night watchman in a hospital. Due to an accident in the building next door, there are deadly fumes rising up through the hospital's ventilation system. In a certain room of the hospital are three patients. In another room there is a single patient. If you do nothing the fumes will rise up into the room containing the three patients and cause their deaths. The only way to avoid the deaths of these patients is to hit a certain switch, which will cause the fumes to bypass the room containing the three patients. As a result of doing this the fumes will enter the room containing the single patient, causing his death.

Would you hit the switch in order to avoid the deaths of the three patients?

6. You work for the Bureau of Health, a government agency. You are deciding whether or not your agency should encourage the use of a certain recently developed vaccine. The vast majority of people who take the vaccine develop an immunity to a certain deadly disease, but a very small number of people who take the vaccine will actually get the disease that the vaccine is designed to prevent. All the available evidence, which is very strong, suggests that the chances of getting the disease due to lack of vaccination are much higher than the chances of getting the disease by taking the vaccine.

Would you direct your agency to encourage the use of this vaccine?

7. You are walking down the street with a friend, and he drops his wallet as he is getting into his car to leave. You open the wallet and find that it contains several hundred dollars and some credit cards. Your friend is wealthy. You, however, have been hit by hard times recently and could really use some extra cash. You consider sending the wallet back to your friend without the cash, keeping the cash for yourself.

Would you keep the money you found in the wallet?

8. You have been trying to find a job lately without much success. You figure that you would be more likely to get hired if you had a more impressive resume. You could put some false information on your resume in order to make it more impressive. By doing this you might ultimately manage to get hired, beating out several candidates who are actually more qualified than you are. Would you put false information on your resume?

\section{Personal Moral Scenarios:}

9. You are a doctor. You have five patients, each of whom is about to die due to failing organs. You have another patient who is healthy. The only way you can save the lives of the first five patients is to transplant five of this young man's organs (against his will) into the bodies of the other five patients. If you do this, the young man will die, but the other five patients will live.

Would you perform this transplant in order to save five of your patients?

10. You are on a cruise ship when there is a fire on board, and the ship has to be abandoned. The lifeboats are carrying many more people than they were designed to carry. The lifeboat you're in is sitting dangerously low in the water - a few inches lower and it will sink. The seas start to get rough, and the boat begins to fill with water. If nothing is done it will sink before the rescue boats arrive and everyone on board will die. However, there is an injured person who will not survive in any case. If you throw that person overboard, the boat will stay afloat and the remaining passengers will be saved.

Would you throw this person overboard in order to save the lives of the remaining passengers?

11. You are the leader of a small group of soldiers. You are on your way back from a completed mission deep in enemy territory when one of your men has stepped in a trap that has been set by the enemy and is badly injured. The trap is connected to a radio device that by now has alerted the enemy to your presence. They will soon be on their way. If the enemy finds your injured man they will torture him and kill him. He begs you not to leave him behind, but if you try to take him with you your entire group will be captured. The only way to prevent this injured soldier from being tortured is to shoot him yourself.

Would you shoot this soldier in order to prevent him from being tortured by the enemy?

12. You are the captain of a military submarine travelling 
underneath a large iceberg. An onboard explosion has caused you to lose most of your oxygen supply and has injured one of your crew who is quickly losing blood. The injured crew member is going to die from his wounds no matter what happens. The remaining oxygen is not sufficient for the entire crew to make it to the surface. The only way to save the other crew members is to shoot dead the injured crew member so that there will be just enough oxygen for the rest of the crew to survive.

Would you kill the fatally injured crew member in order to save the lives of the remaining crew members?

13. It is wartime and you and your two children, ages eight and five, are living in a territory that has been occupied by the enemy. At the enemy's headquarters is a doctor who performs painful experiments on humans that inevitably lead to death. He intends to perform experiments on one of your children, but he will allow you to choose which of your children will be experimented upon. If you refuse to bring on of your children to his laboratory, he will find both of them and experiment on both of them.

Would you bring one of your children to the laboratory in order to avoid having them both die?

14. A viral epidemic has spread across the globe killing millions of people. You have developed two substances in your home laboratory. You know that one of them is a vaccine, but you don't know which one. You also know that the other one is deadly. Once you figure out which substance is the vaccine you can use it to save millions of lives. You have with you two people who are under your care, and the only way to identify the vaccine is to inject each of these people with one of the two substances. One person will live, the other will die, and you will be able to start saving lives with your vaccine. Would you kill one of these people with a deadly injection in order to identify a vaccine that will save millions of lives?

15. You are in a hospital waiting to visit a sick friend. A young man sitting next to you explains that his father is very ill. The doctors believe that he has a week to live at most. He explains that his father has a substantial life insurance policy that expires at midnight. If his father dies before midnight, this young man will receive a very large sum of money. He says that the money would mean a great deal to him and that no good will come from his father's living a few more days. He offers you half a million dollars to go up to his father's room and smother his father with a pillow.

Would you kill this man's father in order to get money for yourself and this young man?

\section{Notes}

1. We also examined the effect of interaction between PPI-I and PPI-II. Regression analyses indicated that the interaction was not statistically significant after controlling for the main effect of gender, PPI-I and PPI-II.

2. Separate analyses were also conducted to examine the potential mediation effects of proactive and reactive aggression on the psychopathy-utilitarian responses relationship. Similar findings were found for both types of aggression.

\section{References}

Antony, M. M., Orsillo, S. M., \& Roemer, L. (2001). Practitioner's guide to empirically based measures of anxiety. New York: Kluwer Academic/Plenum.

Babiak, P., \& Hare, R. D. (2006). Snakes in suits: When psychopaths go to work. New York: HarperCollins.

Bados, A., Gomez-Benito, J., \& Balaguer, G. (2010). The State-Trait Anxiety Inventory, Trait version: Does it really measure anxiety? Journal of Personality Assessment 92(6), 560-567.

Baron, R. M., \& Kenny, D. A. (1986). The moderator-mediator variable distinction in social psychological research: Conceptual, strategic, and statistical considerations. Journal of Personality and Social Psychology, 51(6), 1173-1182.
Bartels, D. M., \& Pizarro, D. A. (2011). The mismeasure of morals: Antisocial personality traits predict utilitarian responses to moral dilemmas. Cognition, 121, 154-161.

Benning, S. D., Patrick, C. J., Hicks, B. M., Blonigen, D. M., \& Krueger, R. F. (2003). Factor structure of the psychopathic personality inventory: validity and implications for clinical assessment. Psychological Assessment, 15(3), 340-350.

Benning, S. D., Patrick, C. J., \& Iacono, W. G. (2005). Psychopathy, startle blink modulation, and electrodermal reactivity in twin men. Psychophysiology, 42, 753-762.

Blonigen, D. M., Hicks, B. M., Krueger, R. F., Patrick, C. J., \& Iacono, W. G. (2005). Psychopathic personality traits: heritability and genetic overlap with internalizing and externalizing psychopathology. Psychological Medicine, 35, 637-648.

Ciaramelli, E., Muccioli, M., Ladavas, E., \& di Pellegrino, G. (2007). Selective deficit in personal moral judgment following damage to ventromedial prefrontal cortex. Social Cognitive and Affective Neuroscience, 2(2), 84-92.

Cima, M., Tonnaer, F., \& Houser, M. D. (2010). Psychopaths know right from wrong but don't care. SCAN, 5, 59-67.

Cohen, J. (1988). Statistical power analysis for the behavioral sciences (2nd ed.). Hillsdale, NJ: Erlbaum.

Coid, J., Yang, M., Ullrich, S., Roberts, A., \& Hare, R. D. (2009). Prevalence and correlates of psychopathic traits in the household population of Great Britain. International Journal of Law and Psychiatry, 32, 65-73.

Edens, J. F., \& McDermott, B. E. (2010). Examining the construct validity of the Psychopathic Personality Inventory-Revised: Preferential correlates of fearless dominance and self-centered impulsivity. Psychological Assessment, 22, 32-42.

Forbes, C. E., \& Grafman, J. (2010). The role of the human prefrontal cortex in socia cognition and moral judgment. Annual Review of Neuroscience, 33, 299-324.

Fowles, D. C., \& Dindo, L. (2009). Temperament and psychopathy: A dual-pathway model. Current Directions in Psychological Science, 18(3), 179-183.

Fumagalli, M., Ferrucci, R., Mameli, F., Marceglia, S., Mrakic-Sposta, S., Zago, S., et al. (2010). Gender-related differences in moral judgments. Cognitive Processing, 11 219-226.

Glenn, A. L., Raine, A., \& Schug, R. A. (2009). The neural correlates of moral decisionmaking in psychopathy. Molecular Psychiatry, 14, 5-6.

Greene, J. D. (2003). From neural "is" to moral "ought": What are the moral implications of neuroscientific moral psychology? Nature Reviews Neuroscience, 4 , $847-850$.

Greene, J. D. (2007). Why are VMPFC patients more utilitarian? A dual-process theory of moral judgment explains. Trends in Cognitive Sciences, 11(8), 322-323.

Greene, J. D., Nystrom, L. E., Engell, A. D., Darley, J. M., \& Cohen, J. D. (2004). The neural bases of cognitive conflict and control in moral judgment. Neuron, 44(2), 389-400.

Greene, J. D., Sommerville, R. B., Nystrom, L. E., Darley, J. M., \& Cohen, J. D. (2001). An fMRI investigation of emotional engagement in moral judgment. Science, 293, $2105-2108$

Hare, R. D. (2003). The Hare Psychopathy Checklist-Revised (PCL-R) (2nd ed.). Toronto, Canada: Multi-Health Systems.

Hartman, K. E. (2007). The honor program: Road to a rehabilitative prison system. (Retrieved on July 112013 from the California State Prison-Los Angeles County Prison Honor Program website: http://www.prisonhonorprogram.org/HONOR\%20PPT/ manual.pdf)

Kiehl, K. A., \& Buckholtz, J. W. (2010, September/October). Inside the mind of a psychopath. Scientific American Mind, 22-29.

Koenigs, M., Kruepke, M., Zeier, J. \& Newman, J. P. (2011). Utilitarian moral judgment in psychopathy. Social Cognitive and Affective Neuroscience, 7(6), 708-714.

Koenigs, M., Young, L., Adolphs, R., Tranel, D., Cushman, F., Hauser, M., et al. (2007). Damage to the prefrontal cortex increases utilitarian moral judgements. Nature 446, 908-911.

Landon, R., \& Delmas, K. (2012). Moral reasoning and psychopathic tendencies in the general community. In R. Langdon, \& C. Mackenzie (Eds.), Emotions, imagination, and moral reasoning: Macquarie Monographs in Cognitive Science (pp. 91-118). New York: Psychology Press.

Lilienfeld, S. O., \& Andrews, B. P. (1996). Development and preliminary validation of a measure of psychopathic personality traits in noncriminal populations. Journal of Personality Assessment, 66, 488-524.

Lilienfeld, S. O., \& Widows, M. R. (2005). Psychopathic Personality Inventory-Revised: Professional manual. Lutz, FL: PAR.

Lynam, D. R., \& Widiger, T. A. (2007). Using a general model of personality to identify the basic elements of psychopathy. Journal of Personality Disorders, 21 $160-178$.

Moretto, G., Ladavas, E., Mattioli, F., \& di Pellegrino, G. (2010). A psychophysiological investigation of moral judgment after ventromedial prefrontal damage. Journal of Cognitive Neuroscience, 22(8), 1888-1899.

Patrick, C. J., Bradley, M. M., \& Lang, P. J. (1993). Emotion in the criminal psychopath: Startle reflex modulation. Journal of Abnormal Psychology, 102, 82-92.

Paulhus, D. L., Hemphill, J. D., \& Hare, R. D. (2012). Manual for the self-report psychopathy scale. Toronto: Multi-health systems.

Porter, S., \& Woodworth, M. (2006). Psychopathy and aggression. Handbook of Psychopathy, 481-494.

Poythress, N., Edens, J. F., \& Lilienfeld, S. O. (1998). Criterion-related validity of the psychopathic personlity inventory in a prison sample. Psychological Assessment, 10, 426-430.

Pujol, J., Batalla, I., Contreras-Rodríguez, O., Harrison, B. J., Pera, V., Hernández-Ribas, R. et al. (2011). Breakdown in the brain network subserving moral judgment in criminal psychopathy. Social Cognitive and Affective Neuroscience, 7(8), 917-923.

Raine, A., Dodge, K., Loeber, R., Gatzke-Kopp, L., Lynam, D. R., Reynolds, C., et al. (2006). The reactive-proactive aggression questionnaire: Differential correlates 
of reactive and proactive aggression in adolescent boys. Aggressive Behavior, 32 , 159-171.

Robertson, D., Snarey, J., Ousley, O., Harenski, K., Bowman, D., Gilkey, R., et al. (2007). The neural processing of moral sensitivity to issues of justice and care. Neuropsychologia, 45(4), 755-766.

Smith, S. T., Edens, J. F., \& Vaughn, M. G. (2011). Assessing the external correlates of alternative factor models of the Psychopathic Personality Inventory - Short Form across three samples. Journal of Personality Assessment, 93(3), 244-256.

Sobel, M. E. (1982). Asymptotic confidence intervals for indirect effects in structural equation models. In S. Leinhardt (Ed.), Sociological Methodology (pp. 290-312). Washington DC: American Sociological Association.

Spielberger, C. D. (1989). State-trait anxiety inventory: A comprehensive bibliography. Palo Alto, CA: Consulting Psychologists Press.
Spielberger, C. D., Gorsuch, R. L., Lushene, R. E., Vagg, P. R., \& Jacobs, G. A. (1983) Manual for the State-Trait Anxiety Inventory STAI (Form Y). Palo Alto, CA: Consulting Psychologists Press.

Uzieblo, K., Verschuere, B., \& Crombez, G. (2007). The Psychopathic Personality Inventory: Construct validity of the two-factor structure. Personality and Individual Differences, 43(4), 657-667.

Warren, G. C. (2009). The relationship between psychopathy and indirect aggression in a community sample. Doctoral of Philosophy. UK: University of York.

Young, L., \& Koenigs, M. (2007). Investigating emotion in moral cognition: a review of evidence from functional neuroimaging and neuropsychology. British Medical Bulletin, 84, 69-79.

Youssef, F. F., Dookeeram, K., Basdeo, V., Francis, E., Doman, M., Mamed, D., et al. (2012). Stress alters personal moral decision making. Psychoneuroendocrinology, 37(4), 491-498. 